\title{
PELUANG BIJIH BESI DALAM PEMENUHAN KEBUTUHAN KOMODITAS MINERAL STRATEGIS NASIONAL
}

\author{
Oleh: \\ Bambang Pardiarto \\ Pusat Sumber Daya Geologi \\ Jl. Soekarno Hatta No. 444 Bandung
}

\begin{abstract}
SARI
Program pemerintah untuk membangun industri baja berbasis bahan baku lokal di Kalimantan Selatan telah dipelopori oleh PT Krakatau Steel bermitra dengan PT Antam (Persero) Tbk yang telah memasuki tahap konstruksi. Selain itu perusahaan ini juga menggandeng Posco untuk mendirikan pabrik baja di Cilegon. Kebutuhan bahan baku berupa bijih besi untuk menopang kedua proyek tersebut sangat besar. Untuk jangka waktu 20 tahun ke depan diperkirakan potensi bijih besi yang ada di Indonesia saat ini tidak akan cukup untuk mensuplai industri baja tersebut. Langkah strategis pemerintah perlu dilakukan agar bijih besi menjadi mineral strategis nasional.
\end{abstract}

Kata Kunci : Bijih besi, mineral strategis

\begin{abstract}
Government program to develop steel industry based on local raw material located in South Kalimantan has been scouted by PT. Krakatau Steel which entered to construction stage. Also the company join to Posco to establish steel industry in Cilegon. The demand of iron ore to support those projects are very large. For the next 20 years the iron ore potential in Indonesia will be not sufficient to supply domestic steel industry. Government strategic policies will be need in order iron ore to become national strategic mineral.
\end{abstract}

Keywords : Iron ore, strategic mineral

\section{PENDAHULUAN}

Perkembangan permintaan bahan baku bijih besi maupun produknya berupa baja pada negara yang berbasis industri menunjukkan trend yang selalu naik. Apalagi dengan kejadian gempa dan tsunami yang melanda Jepang pada bulan Maret 2011, maka permintaan baja dunia juga akan mengalami lonjakan yang signifikan. Hal ini secara langsung akan memberikan dampak yang sangat berarti bagi negara berkembang (Indonesia) terutama dalam kebijakan pengelolaan sumber daya alam khususnya sektor pertambangan pada komoditi bijih besi sebagai salah satu kebutuhan bahan baku industri baja nasional.

Besi merupakan salah satu komoditi logam yang permintaannya selalu meningkat. Pada tahun 2002 produksi bijih besi mencapai lebih dari 1.000 juta ton, sedangkan produksi baja kasar melebihi 900 juta ton untuk pertama kali. Hal ini merupakan pencerminan dari pertumbuhan tinggi yang tidak dapat diperkirakan dari konsumsi dan produksi baja China sejak awal dekade ini. Pertumbuhan produksi baja China sejak tahun 2000 hampir sama dengan produksi di Amerika. Meskipun China memiliki industri bijih besi yang besar namun produksinya tidak mencukupi untuk memenuhi permintaan dalam negeri, sehingga negeri ini sangat tergantung dengan impor. Pertumbuhan yang cepat telah menghilangkan berbagai surplus bijih besi dan meningkatkan harga. 
Tabel 1.

Perbandingan konsumsi, per kapita/tahun produksi baja nasional dan dunia 2000-2009

(Worldsteel Association, 2010)

\begin{tabular}{|c|r|r|r|r|r|r|}
\hline \multirow{2}{*}{ Tahun } & \multicolumn{2}{|c|}{$\begin{array}{c}\text { Konsumsi Baja Kasar } \\
\text { (ribu ton) }\end{array}$} & \multicolumn{2}{c|}{$\begin{array}{c}\text { Konsumsi Baja } \\
\text { Perkapita (Kg) }\end{array}$} & \multicolumn{2}{c|}{$\begin{array}{c}\text { Produksi Baja } \\
\text { (Ribu Ton) }\end{array}$} \\
\cline { 2 - 7 } & Indonesia & \multicolumn{1}{c|}{ Dunia } & Indonesia & \multicolumn{1}{c|}{ Dunia } & Indonesia & \multicolumn{1}{c|}{ Dunia } \\
\hline 2000 & 5.471 & 845.105 & 25,6 & 149,6 & 2.848 & 848.394 \\
\hline 2001 & 5.608 & 855.356 & 25,8 & 149,6 & 2.781 & 851.073 \\
\hline 2002 & 5.422 & 910.986 & 24,6 & 157,6 & 2.461 & 904.170 \\
\hline 2003 & 5.064 & 971.876 & 22,7 & 166,2 & 2.042 & $969 . .915$ \\
\hline 2004 & 6.404 & 1.060 .202 & 28,3 & 179,5 & 3.682 & 1.071 .508 \\
\hline 2005 & 9.084 & 1.134 .208 & 39,7 & 190,0 & 3.675 & 1.144 .136 \\
\hline 2006 & 5.208 & 1.236 .991 & 22,5 & 204,8 & 3.759 & 1.247 .263 \\
\hline 2007 & 6.718 & 1.316 .953 & 28,6 & 217,3 & 4.160 & 1.346 .210 \\
\hline 2008 & 8.707 & 1.300 .722 & 37,1 & 214,3 & 3.915 & 1.329 .123 \\
\hline 2009 & 7.227 & 1.023 .324 & 30,1 & 193,3 & 3.503 & 1.224 .204 \\
\hline
\end{tabular}

\section{Konsumsi dan produksi Baja}

Bijih besi yang merupakan salah satu jenis mineral logam pada saat ini menjadi perhatian karena diperlukan sebagai bahan baku industri baja. Dari tahun ke tahun konsumsi baja dunia mengalami peningkatan yang sangat pesat. Sedangkan konsumsi baja untuk Indonesia sangat berfluktuasi disebabkan antara lain oleh pertumbuhan ekonomi yang kurang stabil . Data dari Worldsteel Association (2010) menunjukkan konsumsi baja dunia sampai dengan tahun 2009 mencapai 1 milyar ton, sedangkan konsumsi baja nasional kita hanya mencapai 7,2 juta ton.

Perkembangan konsumsi baja per kapita pada tingkat dunia dari tahun ke tahun juga mengalami peningkatan, namun secara nasional mengalami fluktuasi. Pada tahun 2009 konsumsi baja per kapita/tahun dunia mencapai $193 \mathrm{~kg}$, sedangkan untuk nasional hanya mencapai $30 \mathrm{~kg}$. Konsumsi baja Indonesia masih jauh lebih rendah jika dibandingkan dengan Malaysia yang sudah mencapai $500 \mathrm{~kg}$. Apalagi jika dibandingkan dengan Korea yang sudah mencapai 1000 kg per kapita/tahun (Firmanti, 2011). Rendahnya konsumsi baja nasional kita merupakan cerminan dari suatu negara berkembang yang belum masuk kategori industrialisasi .

Produksi baja kasar dunia dari tahun ke tahun mengalami peningkatan yang sangat berarti. Data produksi tahun 2000 sampai 2009 menunjukkan produksi tendensinya naik terus. Sedangkan produksi baja nasional kita peningkatannya sangat berfluktuasi. Pada tahun 2009 produksi baja tingkat dunia mencapai 1,2 milyar ton, sedangkan produksi nasional mencapai 3,5 juta ton.

Kondisi produksi besi spon (pig iron) dan baja kasar (crude steel) dunia juga mengalami peningkatan yang berarti, dimana pada tahun 2010 masing-masing sudah mencapai 1 milyar ton dan 1,4 milyar ton ( Tabel 1). 
Pada tahun 2009 China mengimpor hampir $2 / 3$ bijih besi dari total pengekspor dunia dan telah memproduksi pig iron yang mencapai $60 \%$ dari total produksi dunia. Sehingga besarnya konsumsi pig iron China ini menjadi faktor primer penentu perkembangan industri bijih besi internasional. Konsumsi baja dunia tahun 2011 diperkirakan sekitar 950 - 1 milyar ton, dimana produksi baja dunia mencapai 1,2 milyar ton (Herlina, 2010). Kondisi ini diperkirakan akan terjadi surplus baja untuk beberapa saat.

\section{POTENSI BIJIH BESI}

Sekitar $90 \%$ bijih besi dunia berasal dari jenis cebakan besi yang disebut sebagai cherty Banded Iron Formation/ BIF ( Guilbert and Park, 1986). Secara fisik jenis cebakan ini berupa lapisan tipis sedang yang terdiri dari perlapisan besi oksida, besi karbonat atau material besi silika dengan chert atau jasper. Genesa cebakan ini merupakan hasil sedimentasi yang berhubungan dengan proses volkanisme bawah laut pada zaman Pra-Kambrium. Oleh karena itu keterdapatan cebakan ini lebih banyak dijumpai pada negara atau daerah yang secara geologi memiliki fisiografi berupa craton. Kadar ekonomis dari cebakan BIF menurut literatur berkisar antara $25-35 \% \mathrm{Fe}$. Sumber daya besi dunia diperkirakan mencapai 800 milyar ton yang mengandung logam besi mencapai 230 milyar ton (USGS, 2011). Sedangkan cadangan bijih besi diperkirakan sebanyak 180 milyar ton yang mengandung logam besi 87 milyar ton ( Tabel 3).

Tabel 2.

Produksi besi spon dan baja kasar dunia 2009-2010 (juta ton)

\begin{tabular}{|l|r|r|r|r|}
\hline \multirow{2}{*}{ Negara } & \multicolumn{3}{|c|}{ Besi spon } & \multicolumn{2}{c|}{ Baja kasar } \\
\cline { 2 - 5 } & $\mathbf{2 0 0 9}$ & $\mathbf{2 0 1 0}$ & $\mathbf{2 0 0 9}$ & $\mathbf{2 0 1 0}$ \\
\hline Amerika & 19,0 & 29,0 & 59 & 90,0 \\
\hline Brazil & 35,0 & 32,0 & 34 & 33 \\
\hline China & 544 & 600 & 568 & 530 \\
\hline Perancis & 8 & 10 & 33 & 16 \\
\hline Jerman & 20 & 29 & 57 & 44 \\
\hline India & 30 & 39 & 88 & 110 \\
\hline Jepang & 86 & 82 & 53 & 56 \\
\hline Republik Korea & 30 & 31 & 59 & 66 \\
\hline Rusia & 44 & 47 & 30 & 31 \\
\hline Ukraina & 26 & 26 & 10 & 10 \\
\hline Inggris & 87 & 7 & 236 & $\mathbf{1 2 4 0}$ \\
\hline Negara lain & 85 & 67 & $\mathbf{1 0 0 0}$ & $\mathbf{1 4 0 0}$ \\
\hline Total Dunia & $\mathbf{9 3 5}$ & & $\mathbf{1 0 0}$ & 250 \\
\hline
\end{tabular}

Tabel 3. (USGS, Mineral.com.Summaries, Jan. 2011)

Potensi bijih besi dunia (juta ton)

\begin{tabular}{|c|c|c|c|c|}
\hline \multirow[t]{2}{*}{ Negara } & \multicolumn{2}{|c|}{ Produksi tambang } & \multicolumn{2}{|c|}{ Cadangan } \\
\hline & 2009 & 2010 & Bijih & Logam \\
\hline Amerika & 27 & 49 & 6900 & 2100 \\
\hline Australia & 394 & 420 & 24000 & 15000 \\
\hline Brasil & 300 & 370 & 29000 & 16000 \\
\hline Kanada & 32 & 35 & 6300 & 2300 \\
\hline China & 880 & 900 & 23000 & 7200 \\
\hline India & 245 & 260 & 7000 & 4500 \\
\hline Iran & 33 & 33 & 2500 & 1400 \\
\hline Kazakhstan & 22 & 22 & 8300 & 3300 \\
\hline Mauritania & 10 & 11 & 1100 & 700 \\
\hline Meksiko & 12 & 12 & 700 & 400 \\
\hline Rusia & 92 & 100 & 25000 & 14000 \\
\hline Afrika Selatan & 55 & 55 & 1000 & 650 \\
\hline Swedia & 18 & 25 & 3500 & 2200 \\
\hline Ukraina & 66 & 72 & 30000 & 9000 \\
\hline Venezuela & 15 & 16 & 4000 & 2400 \\
\hline Negara lain & 43 & 50 & 11000 & 6200 \\
\hline Total Dunia & 2240 & 2400 & 180000 & 87000 \\
\hline
\end{tabular}

(USGS, Mineral.com.Summaries, Jan. 2011) 


\section{MAKALAH ILMIAH}

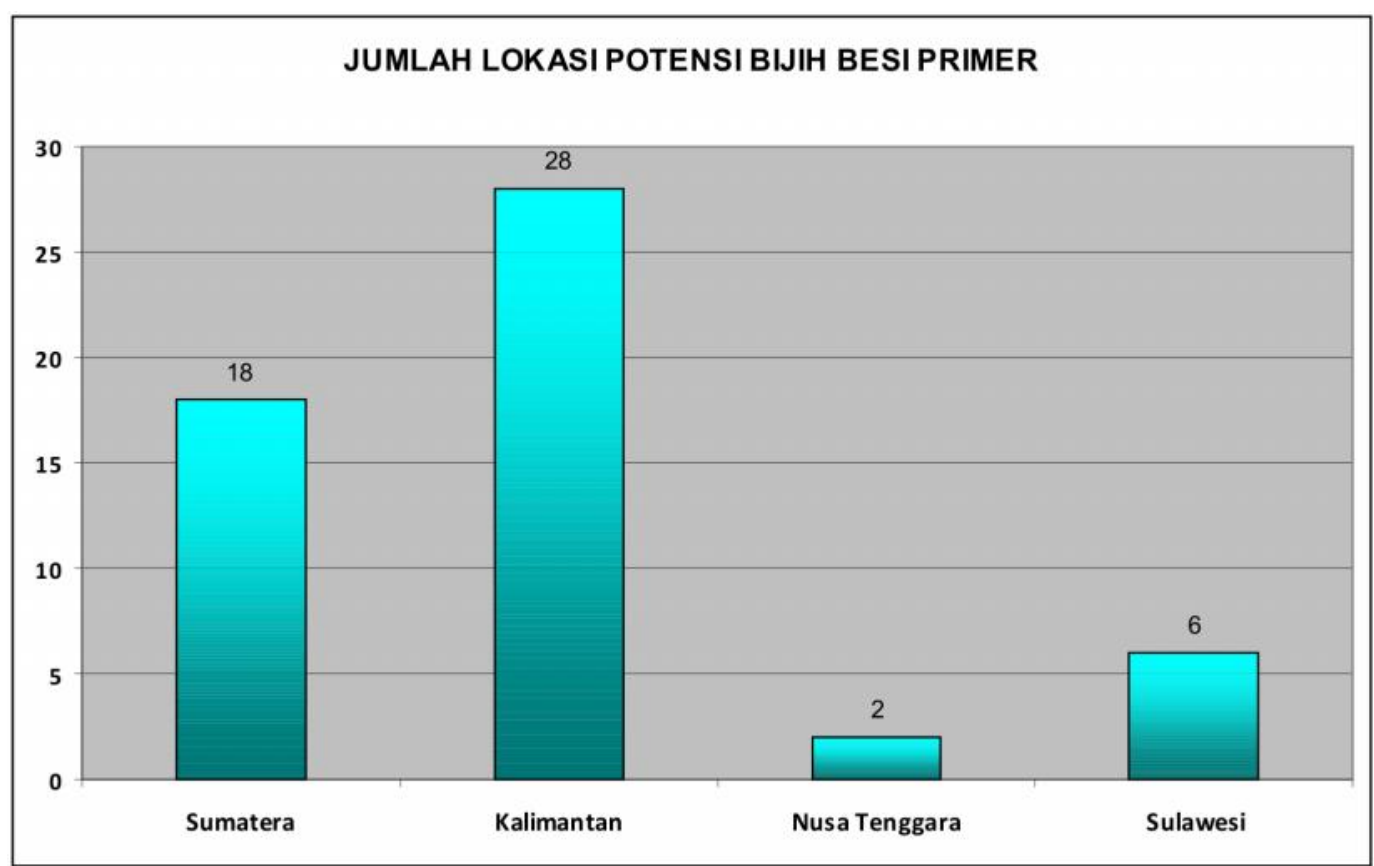

Gambar 1. Diagram jumlah lokasi sumberdaya bijih besi di Indonesia (PSDG, 2010)

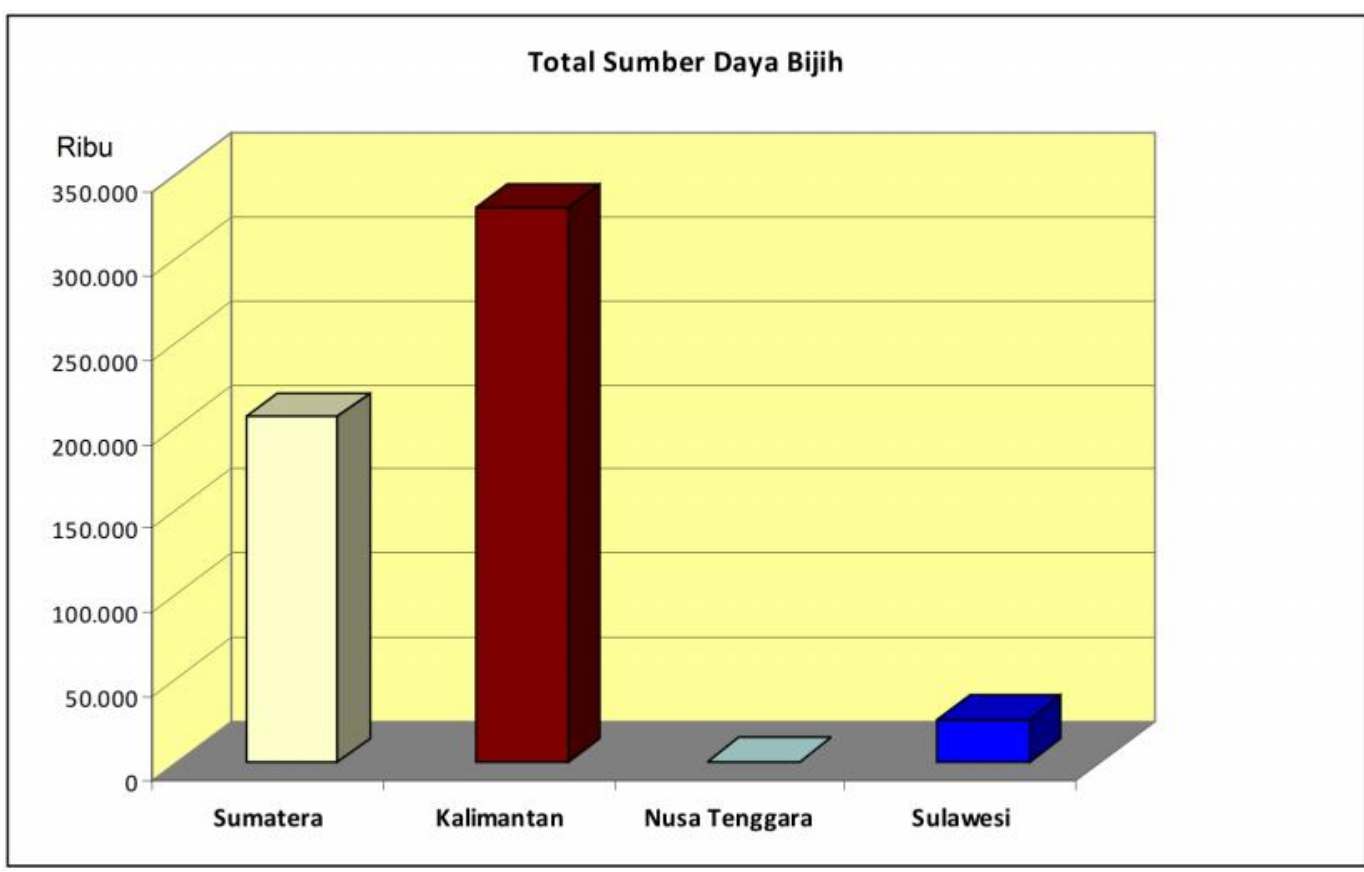

Gambar 2. Diagram total sumberdaya bijih besi Pulau Sumatera, Pulau Kalimantan, Kepulauan Nusa Tenggara dan Pulau Sulawesi ( PSDG, 2010)

Secara geologi wilayah Indonesia hanya merupakan busur magmatis dan tentunya hanya sedikit mempunyai potensi cebakan besi tipe Banded Iron Formation (BIF). Sejauh ini telah ditemukan indikasi terdapatnya cebakan besi tipe BIF di Kabupaten Tanggamus, Lampung (Subandrio, 2006). Namun demikian belum dilakukan evaluasi potensi sumberdaya cebakan bijih besi ini . 
Tabel 4 :

Potensi bijih besi di Indonesia

\begin{tabular}{|l|r|r|r|r|}
\hline \multirow{2}{*}{$\begin{array}{l}\text { Jenis Cebakan } \\
\text { Bijih }\end{array}$} & \multicolumn{2}{|c|}{ Sumber daya (ton) } & \multicolumn{2}{c|}{ Cadangan (ton) } \\
\cline { 2 - 5 } & \multicolumn{1}{|c|}{ Bijih } & \multicolumn{1}{c|}{ Logam } & \multicolumn{1}{c|}{ Bijih } & \multicolumn{1}{c|}{ Logam } \\
\hline Besi Primer & 557.185 .779 & 309.516 .579 & 29.884 .494 & 18.824 .146 \\
\hline Besi Laterit & 1.462 .374 .969 & 591.836 .571 & 106.030 .000 & 24.178 .655 \\
\hline Besi Sedimen & 18.002 .186 & 11.496 .162 & & \\
\hline Pasir Besi & 1.647 .778 .892 & 148.854 .726 & 4.732 .000 & 2.417 .961 \\
\hline
\end{tabular}

(Tim Neraca, PSDG, 2010)

Walaupun demikian, adanya kenaikan permintaan bijih besi dan kenaikan harga baja yang tinggi di pasaran dunia akan membuka peluang untuk eksploitasi endapan bijih besi Indonesia yang bersekala kecil paling tidak untuk memasok kebutuhan bahan baku industri baja dalam negeri.

Pulau Kalimantan dibandingkan dengan pulau-pulau lainnya di Indonesia mempunyai potensi bijih besi yang paling banyak, baik dari jumlah lokasinya maupun sumber daya dan/atau cadangannya. Berdasarkan data neraca sumber daya mineral tahun 2010, terdapat 28 lokasi potensi bijih besi primer di Pulau Kalimantan dengan total sumberdaya 330 juta ton (Gambar 1 dan 2).

Potensi bijih besi di Indonesia dijumpai dalam 4 (empat) jenis cebakan yaitu besi primer, laterit besi , besi sedimen dan pasir besi. Sumber daya dan cadangan dari masing-masing jenis cebakan tersebut tahun 2010 tercatat sebagai berikut (Tabel 4):

\section{KONDISI INDUSTRI BESI BAJA DALAM NEGERI}

PT. Krakatau Steel sebagai satusatunya pabrik baja terintegrasi di Indonesia sejak tahun 1989 memproduksi besi spon (Pig Iron) sebagai bahan baku pembuatan baja kasar (Crude Steel). Teknologi yang digunakan bersifat konvensional yaitu Direct Reduction Process yang menggunakan bahan baku besi pelet dan bahan reduction gas alam. Kapasitas produksi besi spon saat ini adalah 2,3 juta ton/tahun dan memerlukan sebanyak 4,5 juta ton magnetit $\left(\mathrm{Fe}_{3} \mathrm{O}_{4}\right)$ dalam bentuk besi pelet yang seluruhnya diimport dari Swedia dan Brasil. Sedangkan kapasitas produksi baja kasar (Crude steel) nasional adalah 6,5 juta ton/tahun yang memerlukan bahan baku sebanyak 8 juta ton/tahun dalam bentuk besi spon dan scrap baja (Deperind, 2006).

Namun demikian permasalahan yang dihadapi oleh PT. Krakatau Steel adalah tidak adanya pasokan bahan baku dari dalam negeri yang menyebabkan ketergantungan pada pasokan dari luar negeri. Pemerintah mempunyai program yang disebut pengembangan Iron Making Plant. Masih tingginya angka import baja untuk kebutuhan nasional maka akan menjadikan keuntungan bagi pengembangan Iron Making Plant yang menggunakan teknologi konvensional yaitu antara lain :

- Untuk mengurangi ketergantungan bahan baku steel making dari luar negeri

- Kegiatan iron making plant di Indonesia masih kurang

- Mengurangi ketergantungan terhadap scrap dan $\mathrm{HBI}$ impor yang harganya berfluktuasi

- Peluang pemanfaatan bahan baku dalam negeri

- SDM untuk iron making plant khususnya direct reduction sudah siap.

Namun demikian terdapat beberapa kendala pengembangan iron making plant di 
Indonesia antara lain :

- Biaya investasi besar dengan return kecil

- Tersedianya semifinished product (slab/billet) pada pasar dunia sehingga produsen dapat memilih berkonsentrasi pada proses steel-rolling

- Untuk teknologi yang sudah proven bahan baku yang digunakan masih impor( kualitas dan kuantitas bijih besi lokal tidak memenuhi syarat)

Saat ini kondisi pasar baja dunia bergairah yang dipicu oleh permintaan pasar yang besar terutama dari negara besar seperti China dan India yang memicu semakin tingginya harga baja di pasar dunia. Selain itu dipicu oleh kondisi pasca gempa dan tsunami di Jepang pada bulan Maret 2011, maka akan semakin meningkatkan konsumsi baja untuk keperluan terutama pembangunan infrastruktur. Sementara itu di dalam negeri beberapa industri baja hilir menghadapi tekanan akibat tingginya harga baja dunia tersebut

Sebagai gambaran, berdasarkan data Depperin, selama 2006 total produksi baja hulu nasional (iron making) hanya tercatat 2,5 juta ton dibandingkan kebutuhan ideal yang mencapai 6 juta ton. Sementara itu, total kapasitas produksi baja hilir pada tahun yang sama mencapai 24,4 juta. Saat ini industri yang memanfaatkan produk baja hilir semakin banyak seperti industri otomotif, industri galangan kapal, industri elektronik dan industri konstruksi. Namun akibat keterbatasan kapasitas produksi dan juga keterbatasan di bidang teknologi yang dimiliki produsen baja dalam negeri, maka kalangan konsumen industri seperti otomotif dan elektronik lebih memilih mengimpor bahan baku untuk kebutuhan produksinya.

Kondisi ini tidak diantisipasi oleh investor lokal yang hanya mencari keuntungan sesaat yaitu dengan mengeksploitasi bijih besi dan mengekspornya langsung ke luar negeri. Undang-Undang No. 4 Tahun 2009 tentang pertambangan mineral dan batubara telah mengamanatkan pemegang izin usaha pertambangan (IUP) dan izin usaha pertambangan khusus (IUPK) Operasi Produksi wajib melakukan pengolahan dan pemurnian hasil penambangan di dalam negeri. Namun masa transisi saat ini justru dimanfaatkan untuk melakukan ekploitasi sebanyak-banyaknya tanpa mempersiapkan pendirian pabrik pengolahan di dalam negeri.

Beberapa investor telah merencanakan pembangunan pabrik pengolahan bijih besi. Perusahaan tambang bijih besi PT Sebuku Iron Lateritic Ores (SILO) Tbk di Pulau Sebuku, Kotabaru, Kalimantan Selatan akan membangun pabrik pengolahan bijih besi . Selain itu PT Krakatau Steel dan PT ANTAM Tbk bekerjasama merencanakan pembangunan pabrik pengolahan bijih besi dengan nama PT Meratus Jaya Iron \& Steel (MJIS) di Kabupaten Tanah Bumbu. Sejauh ini PT MJIS yang sudah melaksanakan kegiatan konstruksinya.

Dengan adanya pembangunan pabrik besi di Pulau Kalimantan maka aspek transportasi dari lokasi tambang yang tersebar di wilayah ini menjadi keuntungan tersendiri bagi industri hilir. Di satu sisi keberadaan rencana pabrik tersebut masih terpusat di wilayah Provinsi Kalimantan Selatan sedangkan disisi lain potensi bijih besi juga tersebar di wilayah Kalimantan Tengah dan Kalimantan Barat. Oleh karena itu di kedua wilayah tersebut perlu juga dibangun pabrik pengolahan bijih besi (Gambar 3). Keunggulan lokasi maupun sumber daya ini menjadi daya tarik investor untuk mengusahakannya terutama bila dikaitkan dengan keharusan melakukan pengolahan bijih di dalam negeri.

Selain masalah kurangnya pasokan dari industri hulu, masalah tingginya harga baja di pasar dunia juga sangat berpengaruh terhadap perkembangan industri baja di dalam negeri. Seperti diketahui pada tahun 2010 harga HRC di pasar dunia sudah mencapai US\$1.050 per ton per April dari sebelumnya pada Januari masih sekitar US\$710 per ton. Tingginya harga baja dunia ini disebabkan oleh mahalnya harga bahan baku berupa bijih besi dan kenaikan harga minyak dunia.

Melonjaknya harga baja dunia mempengaruhi sejumlah industri hilir baja domestik seperti pabrik seng baja (baja lapis seng) yang terpaksa mengurangi produksi hingga $50 \%$ dan pipa baja yang tidak mampu mengimbangi kenaikan harga bahan baku dengan harga jual produk akhir.

Padahal konsumen yang menggunakan baja seperti industri konstruksi, industri otomotif dan elektronik 


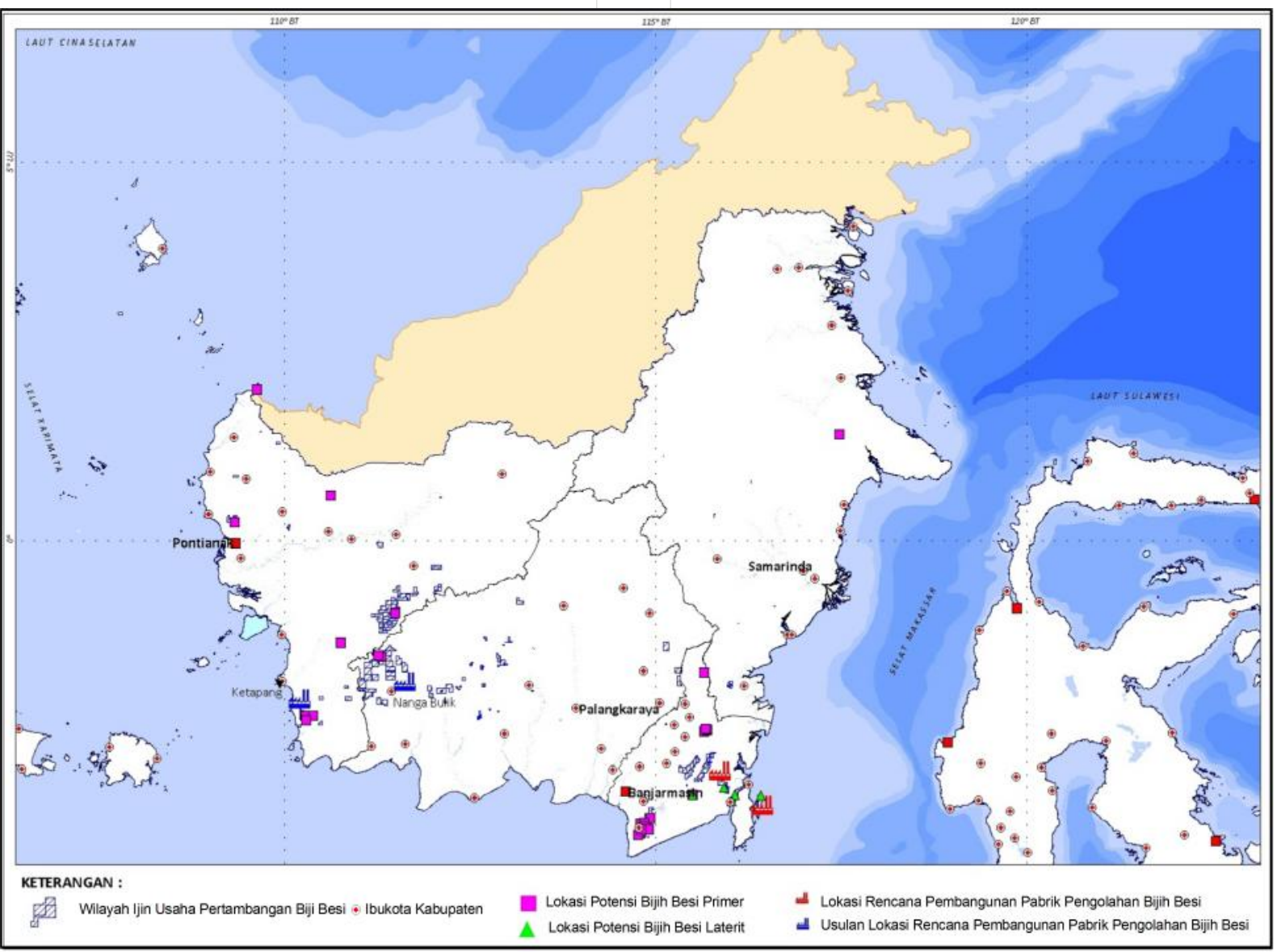

Gambar 3. Peta Sebaran wilayah IUP, Potensi dan Rencana Lokasi Pembangunan Pabrik Pengolahan Bijih Besi ( PSDG, 2010)

masih terus berkembang. Saat ini terlihat kecenderungan pemakaian besi baja yang lebih besar pada pembangunan properti termasuk apartemen, bangunan komersial dan perumahan karena makin mahalnya harga kayu yang pasokannya semakin langka. Permintaan dari sektor otomotif juga meningkat. Produksi mobil meningkat menjadi 325 ribu unit pada 2007 dari tahun sebelumnya 296 ribu unit.

Kegairahan dari industri baja dunia ternyata membawa issue lain yaitu kecenderungan investor asing mengincar pabrik baja di dalam negeri dengan cara akuisisi. Potensi pasar dunia yang saat ini bergairah menyebabkan nilai industri baja semakin tinggi terutama bagi pemain baja dunia yang terintegrasi sehingga bagi mereka tidak ada masalah pasokan bahan baku baja karena dapat dipenuhi dari lingkungan mereka sendiri. Dampak langsung dari kondisi ini adalah terbentuknya kerjasama antara PT. KS dengan Posco (Pohang Steel Corporation) dari
Korea untuk membangun pabrik baja di Cilegon dengan kapasitas produksi 6 juta ton/tahun.

\section{EVALUASI}

Pasokan bahan baku industri besi dan baja sangatlah terbatas. Masalah ini tidak saja dirasakan oleh industri nasional melainkan juga dirasakan oleh industri tingkat dunia. Hal ini terjadi antara lain karena kapasitas produksi yang ada belum mampu mengimbangi kebutuhan yang ada. Pasokan bijih besi di pasar dunia nampaknya sudah banyak terserap oleh China. Untuk hal tersebut terdapat empat perusahaan peleburan baja asal China yang melakukan kontrak dengan pemasok bijih besi dari Australia dengan nilai kontrak mencapai US\$ 9 juta untuk waktu 25 tahun. Ini berarti China akan mendatangkan lebih dari 12 juta ton bijih besi per tahun dari Australia. Prediksi kondisi bijih besi dunia untuk lima tahun kedepan 
Tabel 5.

Perkiraan demand dan suplai bijih besi dunia.

\begin{tabular}{|l|l|l|l|l|l|l|}
\hline & Satuan & $2011 \mathrm{e}$ & $2012 \mathrm{e}$ & $2013 \mathrm{e}$ & $2014 \mathrm{e}$ & $2015 \mathrm{e}$ \\
\hline Total demand & Juta ton & 1.085 & 1.155 & 1.196 & 1.276 & 1.321 \\
\hline Pertumbuhan & $\%$ & 6,6 & 6,4 & 3,5 & 6,7 & 3,5 \\
\hline Total suplai & Juta ton & 1.079 & 1.158 & 1.252 & 1.383 & 1.488 \\
\hline Defisit/surplus & Juta ton & $-6,3$ & 3,0 & 56,5 & 106,9 & 167,5 \\
\hline
\end{tabular}

menurut UBS Invesment Research (2010), perkiraan pada tahun 2011 industri baja dunia akan mengalami defisit pasokan bijih besi yang cukup signifikan yaitu sekitar 6,3 juta ton . Namun pada tahun 2012 kondisi pasaran bijih besi dapat dikatakan normal. Untuk tahun 2013 hingga 2015 akan terjadi kehilangan pasar yang banyak oleh karena kondisi suplai yang lebih besar daripada demand (Tabel5).

Program revitalisasi PT KS yang menghabiskan dana kurang lebih US\$ 570 juta yang meliputi pengembangan teknologi blast furnace senilai US\$ 220 juta dan untuk modernisasi US\$ 350 juta, maka besi dengan kadar rendah yang mendominasi endapan bijih besi di Indonesia akan dapat diolah didalam negeri. Sehingga hal ini berdampak pada total $100 \%$ impor bijih besi yang selama ini dilakukan PT KS dapat dikurangi ( Suhendra, 2010).

Kondisi kapasitas produksi baja terutama oleh industri strategis nasional PT KS saat ini mencapai 2,55 juta ton/tahun yang menggunakan tekonologi DR Hyl-3 (Direct Reduction) dan BF KS (Blast Furnace) masing-masing berkapasitas 1,35 dan 1,2 juta ton/tahun. Sedangkan kebutuhan bahan baku bijih besi untuk membuat baja di Indonesia terutama oleh PT KS , hampir seluruhnya masih diimpor dari negara lain berupa pelet dalam jumlah yang cukup besar. Hal ini karena spesifikasi bijih besi yang ada di Indonesia masih dianggap belum cocok untuk digunakan sebagai bahan baku bagi industri besi baja nasional. Kondisi ini mengakibatkan berkurangnya devisa negara dan kurang kokohnya fundamental industri baja tersebut karena besarnya ketergantungan bahan baku impor.

Untuk menjamin kelancaran proses industri besi baja di PT KS saat ini dan rencana pengembangan kapasitas produksi dimasa mendatang, perlu dukungan penyediaan bahan baku bijih besi dalam jumlah yang cukup dan harga yang kompetitif. Sampai saat ini kebutuhan bijih besi nasional masih diimpor dari luar negeri seperti dari Brazil, Peru, Canada dan lainnya. Dari potensi yang ada baru sebagian kecil bahan tambang tersebut yang dimanfaatkan untuk kebutuhan industri besi-baja di Indonesia. Dalam perkembangan global diperkirakan akan terjadi kecenderungan defisit pasokan bijih besi dunia yang mengakibatkan keberadaan bijih besi semakin langka dan mahal harganya.

Berkaitan dengan peningkatan kapasitas produksi baja PT KS telah melakukan kerjasama dengan Posco salah satu produsen baja dari Korea Selatan yang kapasitas produksinya mencapai 30,5 juta/tahun. Kerja sama pembangunan pabrik akan dilakukan dua tahap yang akan memerlukan dana sekitar US\$ 6 milyar dengan kapasitas produksi baja 6 juta ton/tahun. Untuk tahap pertama akan dibangun pabrik berkapasitas 3 juta ton/tahun yang akan selesai tahun 2013 dengan investasi US\$ 2,5- 3 milyar dengan produk seperti HRC, slab dan plate. Pemancangan tiang tahap pertama dilakukan bulan Juli 2011 dan diharapkan akan mulai berproduksi tahun 2014. Lokasi pabrik baja patungan ini dengan luas 350 hektar berada di Krakatau Industrial Estate Cilegon, Banten (Suhendra, 2010).

Berkaitan dengan strategi pengembangan iron making maka upaya yang ditempuh oleh PT KS melalui PT MJIS yang bermitra dengan PT Antam (Persero) Tbk ini dikenal menggunakan jalur quick win yaitu pengembangan pabrik iron making sekala kecil dengan kapasitas kurang lebih 300 ribu ton/tahun, biaya investasi sekitar Rp. 596 milyar. Jalur ini mempunyai keuntungan sebagai berikut (Deperind, 2007):

- Pembangunan dapat direalisasikan dalam waktu cepat

- Hasil produksi berupa besi spons yang akan 


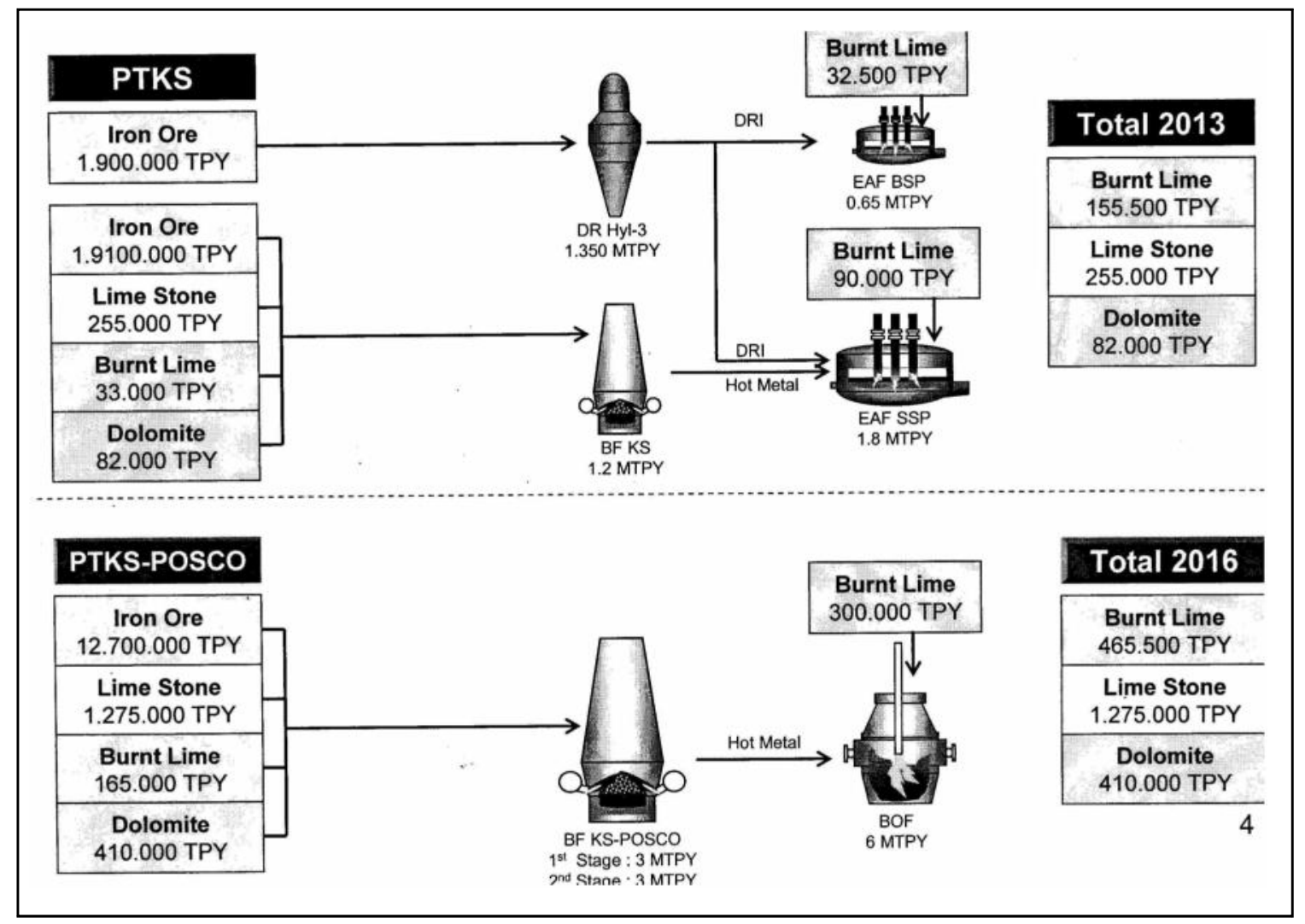

Gambar 4. Skenario kebutuhan bahan baku bijih besi PT. Krakatau Steel (Kusno, 2011)

Tabel 6.

Resume sumberdaya dan cadangan bijih besi di Pulau Kalimantan ( PSDG, 2010)

\begin{tabular}{|l|l|l|l|l|}
\hline \multirow{2}{*}{ Wilayah } & \multicolumn{2}{|c|}{ Total Sumberdaya (ton) } & \multicolumn{2}{c|}{ Total Cadangan (ton) } \\
\cline { 2 - 5 } & Besi primer & Besi laterit & Besi primer & Besi laterit \\
\hline Pulau Kalimantan & 319.307 .707 & 485.345 .835 & 24.091 .005 & 3.644 .183 \\
\hline Kalimantan Selatan & 10.071 .860 & 485.345 .835 & $3.737 .890 *$ & $3.644 .183 * *$ \\
\hline
\end{tabular}

*) Produksi 1.521.885 ton (2010) dikonversi ke cadangan terbukti

**) Produksi 3.664.183 ton (2010) dikonversi ke cadangan terbukti

Tabel 7.

Perbandingan antara kebutuhan bijih besi dengan cadangan untuk masa 20 tahun.

\begin{tabular}{|l|l|l|l|}
\hline Proyek Kerjasama & $\begin{array}{l}\text { Kebutuhan bahan } \\
\text { baku bijih besi (ton) }\end{array}$ & $\begin{array}{l}\text { Cadangan tersedia } \\
\text { (ton) }\end{array}$ & Defisit (ton) \\
\hline PT. MJIS & 12.000 .000 & 2.216 .005 & 9.783 .995 \\
\hline $\begin{array}{l}\text { PT. KS dan JV } \\
\begin{array}{l}\text { PT.KS+Posco di } \\
\text { Cilegon, Jabar }\end{array}\end{array}$ & 314.000 .000 & 39.803 .868 & 274.196 .132 \\
\hline
\end{tabular}


diolah lebih lanjut dengan fasilitas existing yang ada di Cilegon.

- Memanfaatkan infrastruktur dan pemasok yang telah ada di Kalimantan Selatan. Industri iron making PT MJIS yang berlokasi dikawasan Kapet Tanah Bumbu di Kalimantan Selatan merencanakan produksi berupa besi spons ditargetkan sekitar 315.000 ton/ tahun sebagai bahan baku pengolahan baja di PT KS di Cilegon, Banten (Bambang P, 2009). Sehingga industri ini akan memerlukan pasokan bijih besi sekitar 600.000 ton/tahun dengan kadar $\mathrm{Fe}>57 \%$.

Sementara itu kebutuhan industri PT KS sendiri yang pabriknya ada di Cilegon dengan produksi baja 2.500 .000 ton/tahun memerlukan bijih besi sebanyak 3.000.000 ton/tahun. Selain itu untuk industri baja baru patungan antara PT KS dan Posco dengan rencana produksi baja 6.000.000 ton/tahun akan memerlukan bijih besi sebanyak 12.700.000 ton/tahun (Gambar 4).

Dari ketiga industri tersebut perkiraan total kebutuhan bijih besi untuk industri baja PT KS dan industri patungan PT KS-Posco secara keseluruhan akan mencapai 16.300.000 ton/tahun. Kalau kita asumsikan umur industri tersebut paling lama 20 tahun maka total bijih besi yang diperlukan sebanyak 326.000.000 ton.

Dengan demikian kebutuhan bijih besi industri PT KS secara keseluruhan akan mencapai 16.300.000 ton/tahun diantaranya 600.000 ton/tahun untuk proyek PT MJIS di Kalimantan Selatan. Sehingga jika PT MJIS tersebut beroperasi untuk selama 20 tahun akan memerlukan bahan baku bijih besi sebanyak 12.000.000 ton. Hasil inventarisasi di Pulau Kalimantan potensi bijih besi secara keseluruhan dapat diresumekan sebagai berikut (Tabel 6 ):

Dengan demikian secara teoritis jika perbandingan antara total cadangan bijih besi di Kalimantan Selatan yang tersisa sampai dengan tahun 2010 sebanyak 2.216.005 ton dengan kebutuhan bahan baku untuk proyek industri besi baja Kalsel selama 20 tahun sekitar 12.000.000 ton maka akan terdapat defisit bahan baku yang cukup besar yaitu sebanyak 9.783 .995 ton. Sedangkan untuk kebutuhan bahan baku industri baja PT KS maupun Joint Venture PT KS + Posco di Cilegon, Banten untuk selama 20 tahun akan mengalami defisit sebanyak 274.196.132 ton ( Tabel 7).

Berdasarkan evaluasi tersebut maka kebutuhan bijih besi pada proyek PT. MJIS khususnya di Kalimantan Selatan akan mengalami defisit bahan baku yang cukup signifikan. Untuk memecahkan masalah ini diperlukan beberapa solusi antara lain :

- Meningkatkan kegiatan eksplorasi untuk menaikkan status potensi sumberdaya hipotetik menjadi cadangan. Hal ini mutlak dilakukan mengingat potensi sumberdaya masih banyak. Kegiatan eksplorasi geofisika dengan metoda ground magnetic yang ditindaklanjuti dengan pemboran inti sangat efektif untuk peningkatan status potensi ini.

- Menerapkan teknologi metalurgi yang tepat dengan umpan bijih besi berkadar rendah. Penyesuaian teknologi diperlukan mengingat sebagian potensi yang ada umumnya merupakan bijih besi tipe laterit yang berkadar rendah. Salah satu cara adalah dengan teknik magnetizing roasting yang diikuti dengan pemisahan magnetik untuk menghasilkan konsentrat magnetik dengan kandungan besi tinggi

(Pramusanto dan Saleh, 2005).

- Mendapatkan jaminan pasokan bahan baku melalui campur tangan aparat pemerintah Kabupaten Tanah Bumbu dan Kotabaru untuk membuat kebijakan agar dapat mendorong para calon pemasok seperti PT SILO dan perusahaan lainnya untuk bersedia memenuhi kebutuhan proyek PT MJIS baik jumlah, kualitas maupun jangka waktu pasokan.

- Untuk jaminan pasokan jangka panjang selain dari perusahaan yang sudah berproduksi di wilayah ini, hendaknya konsorsium melaksanakan penguasaan lahan pertambangan bijih besi demi keamanan pasokan tersebut.

- Kekurangan bijih besi primer dapat diambil dari wilayah diluar Kalimantan Selatan seperti di Kalimantan Tengah dan Kalimantan Barat yang sudah banyak perusahaan melakukan penambangan.

Dalam bab penjelasan Undang Undang Nomor 4 tahun 2009 pada pasal 27 dinyatakan besi menjadi salah satu dari tujuh komoditas mineral logam lainnya untuk dijadikan pencadangan negara pertambangan dalam usaha untuk ketahanan energi dan industri strategis nasional. Hasil evaluasi kebutuhan bijih besi industri baja PT. KS untuk masa produksi selama 20 tahun akan terjadi defisit bijih besi dengan total mencapai 283.980.127 ton. Untuk memenuhi kebutuhan ini maka impor bijih besi dari mancanegara menjadi alternatif lainnya sepanjang secara ekonomi masih menguntungkan perusahaan. Namun apabila secara ekonomi impor tidak menguntungkan maka pemerintah harus mengeluarkan kebijakan strategis agar pengelolaan bijih besi ini sepenuhnya menjadi tanggungan negara demi menjaga kelangsungan industri strategis nasional seperti PT KS.

Sejalan dengan ketentuan perundangan maka setelah tahun 2014 ekspor bijih besi hanya boleh dilakukan setelah ada peningkatan nilai tambahnya. Namun apabila fasilitas 
infrastruktur belum tersedia maka pemerintah seyogyanya tetap melarang kegiatan ekspor dalam bentuk bahan mentah sambil menunggu selesainya pembangunan. Sehingga sumberdaya yang masih tersisa diharapkan dapat menjamin kelangsungan industri baja dalam negeri.

Berkaitan dengan lingkungan khususnya potensi bijih besi yang tumpang tindih dengan kawasan lindung, maka pemerintah akan mengeluarkan kebijakan strategis yaitu daerah potensi tersebut akan ditetapkan menjadi wilayah izin usaha pertambangan khusus (WIUPK) agar dapat dimanfaatkan untuk mendukung kebutuhan bahan baku industri dalam negeri.

Dengan demikian untuk kebutuhan jangka panjang maka peluang besi menjadi komoditas strategis nasional sangat besar untuk diterapkan mulai saat ini di Indonesia.

\section{PENUTUP}

Perkembangan global konsumsi baja yang semakin meningkat telah memicu industri baja untuk meningkatkan kapasitas produksinya. Akibatnya produksi bijih besi juga mengalami peningkatan yang signifikan. Hal ini diperkirakan suatu saat akan menimbulkan kelangkaan dan krisisnya bahan baku untuk industri baja ini. Hasil evaluasi kebutuhan bijih besi untuk industri baja PT. Krakatau Steel untuk beroperasi selama 20 tahun akan mengalami defisit sebanyak 283.980.127 ton. Dengan demikian cukup beralasan bijih besi menjadi komoditas mineral strategis nasional yang dikelola oleh negara. Untuk itu dalam jangka panjangnya diperlukan kebijakan pemerintah yang mendukung kepentingan strategis nasional ini .

\section{UCAPAN TERIMAKASIH}

Penulis menyampaikan terima kasih kepada editor khususnya kepada Dr.Ir.Bambang T. Setiabudi M.Sc. yang telah memberikan masukan dan saran untuk perbaikan makalah ini.

\section{DAFTAR PUSTAKA}

Firmanti, A., 2011, Konsumsi baja nasional, Seminar future prospect of steel construction in Indonesia, Gran Melia, Jakarta 7 April 2011.

Herlina K.D, 2010, Tahun depan harga baja naik 10-15\%, http:// industri.kontan.co.id

Kusno, 2011, Kebutuhan flux materials, diskusi non formal, Bandung.

Suhendra, 2010, Industri baja minta ekspor bijih besi kena bea keluar, Detik Finance.

Pardiarto, B., 2009, Tinjauan rencana pembangunan industri besi baja di Kalimantan Selatan, Buletin Sumber Daya Geologi, Volume 4 Nomor 2, 2009.

Pramusanto; Saleh, N., 2005, Coal based magnetizing roasting for iron cap ore of lateritic ore, IMAMining Conference 2005, Jakarta.

Subandrio, A.S.M, 2006, Indonesian Banded Iron Formation (BIF) : A new challenge of iron deposit by controversial discovery of BIF in Tanggamus area- Lampung, South Sumatera, Proceedings of 9th International Symposium on Mineral Exploration (ISME IX), September 19-21 th 2006, Bandung, Indonesia.

Tim Neraca, 2010, Laporan penyusunan neraca sumber daya mineral, Pusat Sumber Daya Geologi (unpublished)

, 2003; Kebutuhan Mineral Logam Dalam Industri Nasional, Seminar Supply Demand Mineral dan Batubara Serta Pengawasannya, Direktorat Industri logam Mesin dan Maritim, Jakarta.

, 2006, Perkembangan rencana pembangunan industri iron making di Kalimantan Selatan, Simposium nasional pengembangan industri baja, Deperind, Jakarta 23 Maret 2006.

........., 2010, Laporan Kajian Besi di Kalimantan, Pusat Sumber Daya Geologi (unpublished).

..........2010, Steel statistical year book 2009, World steel association, Worldsteel committee on economics studies, Brussel. ( worldsteel.org ) 
2010, UBS Global I/O : Iron ore, 8 November 2010, UBS Invesment Research, www.wpgresources.com.au.

., 2011, Mineral Commodity Summaries, US Geological Survey

Diterima tanggal 11 April 2011

Revisi tanggal 16 Juli 2011 